\title{
Atherogenesis in the Carotid Artery with and without Interrupted Blood Flow of Two Hyperlipidemic Mouse Strains
}

\author{
Jian Zhao ${ }^{a, b}$ Chaoji Huangfu ${ }^{a, c}$ Zhihui Chang ${ }^{a, b}$ Andrew T. Grainger ${ }^{d}$ \\ Zhaoyu Liu ${ }^{b}$ Weibin Shi ${ }^{a}$ d \\ ${ }^{a}$ Department of Radiology and Medical Imaging, University of Virginia, Charlottesville, VA, USA; ${ }^{b}$ Department \\ of Radiology, Shengjing Hospital of China Medical University, Shenyang, China; ' Center for Disease Control and \\ Prevention, Western Theater Command, Lanzhou, China; ${ }^{d}$ Department of Biochemistry and Molecular Genetics, \\ University of Virginia, Charlottesville, VA, USA
}

\section{Keywords}

Atherosclerosis · Carotid artery · Hyperlipidemia · Genetic background · Blood flow

\section{Abstract}

Purpose: Atherosclerosis in the carotid arteries is a common cause of ischemic stroke. We examined atherogenesis in the left carotid artery with and without interrupted blood flow of $\mathrm{C} 57 \mathrm{BL} / 6$ (B6) and $\mathrm{C} 3 \mathrm{H}-$-Apoe-deficient $\left(\mathrm{Apoe}^{-/-}\right)$mouse strains. Methods: Blood flow was interrupted by ligating the common carotid artery near its bifurcation in one group of mice and another group was not interrupted. Results: Without interference with blood flow, $\mathrm{C} 3 \mathrm{H}-\mathrm{Apoe}^{-/-}$mice developed no atherosclerosis in the carotid artery, while B6Apoe $^{-/-}$mice formed advanced atherosclerotic lesions $\left(98,019 \pm 10,594 \mu \mathrm{m}^{2} /\right.$ section $)$ after 12 weeks of a Western diet. When blood flow was interrupted by ligating the common carotid artery near its bifurcation, $\mathrm{C} 3 \mathrm{H}-\mathrm{Apoe}^{-/-}$mice showed fatty streak lesions 2 weeks after ligation, and by 4 weeks fibrous lesions had formed, although they were smaller than in B6-Apoe ${ }^{-/-}$mice. Neutrophil adhesion to endothelium and infiltration in lesions was observed in ligated arteries of both strains. Treatment of B6-Apoe ${ }^{-/-}$mice with anti- body against neutrophils had little effect on lesion size. Conclusions: These findings demonstrate the dramatic influences of genetic backgrounds and blood flow on atherogenesis in the carotid artery of hyperlipidemic mice.

(c) 2019 S. Karger AG, Base

\section{Introduction}

Stroke is the leading cause of disability in adults and the fourth most common cause of death in the USA [1]. Ischemic stroke, resulting from the obstruction of blood flow to the brain, accounts for $83 \%$ of all stroke cases. Atherosclerosis in the carotid arteries leads to changes ranging from minor wall thickening to hemodynamically significant luminal stenosis and constitutes one of the major causes of ischemic stroke, including transient ischemic attacks and cerebral infarction [2-4]. Carotid atherosclerosis may occur concomitantly with atherosclerosis in other arterial beds, such as coronary and femoral arteries, or occur in isolation $[2,5,6]$. Because atherosclerosis in the aorta is easy to measure in mice, previous studies of this disease with the rodent have almost entirely focused on this vessel.
(C) 2019 S. Karger AG, Base 
We and others have established a mouse model of carotid atherosclerosis in which blood flow in the common carotid artery of C57BL/6 (B6) Apoe null $\left(\mathrm{Apoe}^{-/-}\right)$mice is interrupted by partially or completely ligating the vessel or its branches [7-10]. This leads to the development of atherosclerosis at a faster rate than common atherosclerosis in the vessel without interruption of blood flow. Lesions in the ligated artery rapidly progress from a fatty streak consisting of macrophage-derived foam cells, to a fibrous plaque involving smooth muscle cells, to an advanced lesion containing neovessels, all of which occurs within 4 weeks. Lesion formation in this model is markedly accelerated by feeding with a Western diet, as seen in the mouse models of common atherosclerosis [1113].

Previous studies from our group and others have shown that there exists a wide range of variation in atherogenesis among mouse strains [13-15]. $\mathrm{B} 6$ and $\mathrm{C} 3 \mathrm{H}$ are the most divergent mouse strains in terms of variation in aortic lesion formation. When fed an atherogenic diet containing high fat/cholesterol and cholate or deficient in Apoe, strain B6 develops much larger atherosclerotic lesions in the aorta than $\mathrm{C} 3 \mathrm{H}$ mice $[11,14]$. Because atherosclerosis develops in a site-specific manner, especially when blood flow is altered [16], the goal of this study was to determine the influence of genetic background on atherosclerosis development in the carotid artery using the Apoe $^{-/-}$mouse model.

\section{Materials and Methods}

\section{Mice}

B6-Apoe ${ }^{-/-}$mice purchased from the Jackson Laboratory were bred to generate the mice used in this study. C3H-Apoe ${ }^{-/-}$mice were created in our lab using the classical congenic breeding protocol [13]. Mep1 $\alpha^{-/-}$mice, provided by Dr. Christoph Becker-Pauly from the University of Kie, Germany, were bred onto the B6Apoe $^{-/-}$background. Mice were weaned at 3 weeks of age onto a chow diet. One group of mice were switched onto a Western diet containing $21 \%$ fat, $48.5 \%$ carbohydrate, $17 \%$ protein, and $0.2 \%$ cholesterol (by weight; Envigo, TD 88137) 1 week before surgery and remained on the diet thereafter. Another group was started with the Western diet at 6 weeks of age and remained on the diet for 12 weeks to evaluate the common type of atherosclerosis in the carotid artery.

\section{Surgical Procedure}

The procedure for ligating the left common carotid artery was performed as previously described [8]. Briefly, 4- to 8-week-old mice of both sexes were anesthetized by intramuscular injection with ketamine ( $80 \mathrm{mg} / \mathrm{kg}$ body weight; Ketaset, Aveco Inc.) and xylazine ( $8 \mathrm{mg} / \mathrm{kg}$; AnaSed, Lloyd Laboratories). Under sterile conditions, a midline incision was made in the front of the neck, then the left common carotid artery was dissected under a microscope and ligated near the bifurcation to completely block blood flow (Fig. 1). The surround tissues were then returned and the incision of the skin was closed with a surgical glue (Vetclose ${ }^{\mathrm{TM}}$, Henry Schein Animal Health). After the procedure, mice continued on the Western diet.

\section{Tissue Preparation and Lesion Quantification}

Mice receiving carotid artery ligation were euthanized at 1 or 3 days or 1,2, or 4 weeks after surgery with prolonged exposure to isoflurane inhalation, as reported [8]. The vasculature was flushed first with saline and then with $10 \%$ formalin via the left ventricle of the heart. The neck was dissected en bloc and further fixed in $10 \%$ formalin for $>48 \mathrm{~h}$. After fixation, the front soft tissues of the neck including the left and right common carotid arteries were dissected out, embedded in OCT compound (Tissue-Tek, Miles Inc.), and cross-sectioned at a thickness of $10 \mu \mathrm{m}$. Serial sections were collected, starting from the disappearance of the ligation suture, and mounted on poly-D-lysine-coated slides with 8 sections per slide. Approximately 300 sections were collected from each mouse. Three evenly spaced slides were chosen for hematoxylin and eosin (HE) staining (Fig. 1). One section on each stained slide was chosen for morphometric measurements of the ligated left common carotid artery and the contralateral right common carotid artery using Zeiss AxioVision 4.8 software. Luminal area and areas encircled by the internal and external elastic laminae were measured. The lesion area was calculated by subtracting the luminal area from the area within the internal elastic lamina, and the medial area of the arterial wall was calculated by subtracting the area encircled by the internal elastic laminae from the area within the external elastic laminae. Measurements made from 3 separate slides were averaged for each vessel and this average was used for statistical analysis. For visualization of neutral lipid, selected sections were stained with oil red $\mathrm{O}$ and hematoxylin, counterstained with fast green [17]. Mice that received no surgery were euthanized after 12 weeks of Western diet to measure primary atherosclerosis in the left common carotid artery and its main branches, as previously reported [18].

\section{Immunohistochemical Analysis}

Immunohistochemical staining for leukocyte-specific antigens and smooth muscle cell $\alpha$-actin was performed on frozen sections of the carotid arteries using the following primary antibodies: rat anti-mouse Ly6G antibody (RB6-8C5, eBioscience), rat anti-mouse CD4 antibody (MABF415, Millipore), rabbit antimouse CD8 IgG (D4W2Z, Cell Signaling), rat anti-mouse macrophage/monocyte IgG, clone MOMA-2 (MCA519GT, Serotec), mouse anti-human $\alpha$-smooth muscle actin IgG (M085129, Dako), goat polyclonal antibody for FPR1 from Santa Cruz (sc-13198), and rat anti-mouse Mac-3 IgG1 (Clone M3/84) from BD Biosciences. Subsequent incubations with biotinylated secondary antibody and visualization with a Vectastain Elite ABC HRP Kit (Vector Laboratories) were performed as previously described [19]. Sections stained with goat anti-rat IgG $(\mathrm{H}+\mathrm{L})$ Alexa Fluor 488 (4416S, Cell Signaling), donkey anti-goat IgG $(\mathrm{H}+\mathrm{L})$ antibodyNL557 (NL001, R\&D Systems), or DAPI fluoromount-G (010020 , Southern Biotech) were directly visualized under fluorescence microscopy. 
Plasma Lipid Measurements

Fasting blood was collected via retro-orbital sinus puncture under isoflurane anesthesia immediately before the mice were euthanized. Enzymatic assays for total and high-density lipoprotein (HDL) cholesterol and triglycerides were performed using cholesterol and triglyceride kits from Thermo DMA (Louisville, CO, USA) [12]. Non-HDL was calculated as the difference between total and HDL cholesterol levels.

\section{Flow Cytometric Analysis of Blood Neutrophils and}

T Lymphocytes

Blood was collected from non-fasted male B6-Apoe ${ }^{-/-}$and $\mathrm{C} 3 \mathrm{H}-\mathrm{Apoe}^{-/-}$mice under isoflurane anesthesia through retro-orbital plexus puncture. Red blood cells were lysed with ACK buffer (ThermoFisher, A1049201). The remaining cells were subjected to flow cytometric analysis of neutrophils and $\mathrm{T}$ cells as previously reported $[20,21]$. Neutrophils were evaluated with fluorescence conjugated monoclonal antibodies, including BV421-conjugated rat anti-mouse Ly6G (BD Biosciences, cat. No. 562737), APC-conjugated rat anti-mouse CD11b (eBiosciences, cat. No. 17-0012-81), and Percp-conjugated anti-mouse CD45 (eBioscience, cat. No. 450451-80). T cells were determined with FITC-conjugated antiCD4 (eBioscience, cat. No. 11-0043-81), efluor 450-conjugated CD8a (eBioscience, cat. No. 48-0081-80), and Percp-conjugated anti-mouse CD45. Neutrophils were defined as cells double positive for CD11b and Ly6G within a CD45-positive population. T cells were identified as cells positive for CD4 or CD8 in a CD45positive population.

\section{Antibody Treatment}

For neutrophil depletion experiments, Mepla ${ }^{-/-} \mathrm{Apoe}^{-/-}$mice on a B6 genetic background, which show increased neutrophil infiltration in atherosclerotic lesions (unpubl. data), were intraperitoneally injected with $200 \mu \mathrm{g}$ of monoclonal rat anti-mouse Ly6G antibody (clone: 1A8, Biolegend) per mouse every other day for 4 weeks, starting the day before surgery. For mice that were not treated with the antibody, an equivalent amount of saline was administered as reported [22].

\section{Statistical Analysis}

Data are expressed as the mean \pm SE, with $n$ indicating the number of animals. Analysis of variance (ANOVA) or Student's $t$ test was used to determine the statistical significance for differences between strains or treatments in various measurements. Differences were considered statistically significant at $p \leq 0.05$.

\section{Results}

\section{Fasting Plasma Lipid Levels of Two Apoe ${ }^{-/-}$Mouse}

\section{Strains}

Fasting plasma levels of total and HDL cholesterol and triglyceride were measured for female $\mathrm{B} 6-\mathrm{Apoe}^{-/-}$and $\mathrm{C} 3 \mathrm{H}-\mathrm{Apoe}^{-/-}$mice after being fed a Western diet for 12 weeks. Non-HDL cholesterol was calculated as the difference between total and HDL cholesterol levels. Both strains developed severe dyslipidemia with elevated non-

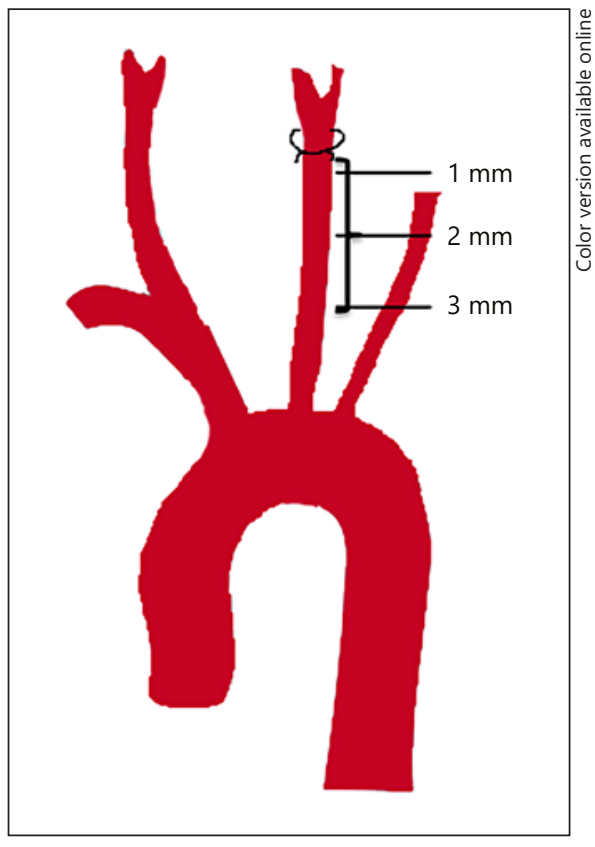

Fig. 1. A schematic diagram showing the location of ligation on the left common carotid artery of mice and the levels of 3 cross-sections used for morphometric analysis.

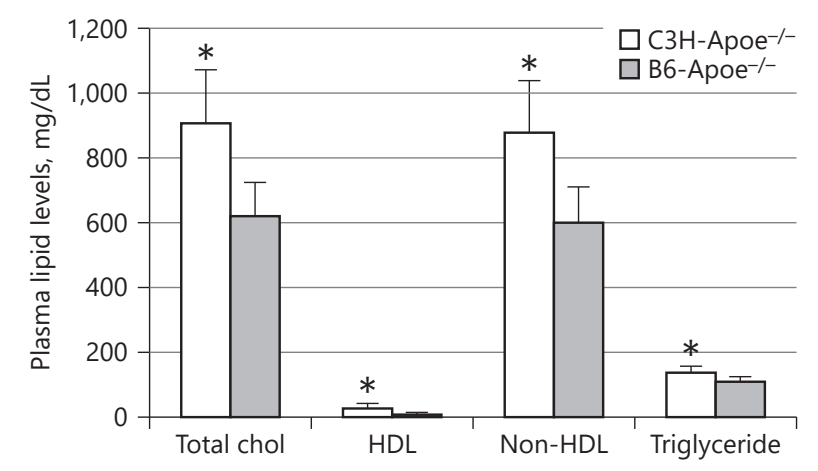

Fig. 2. Plasma levels of total cholesterol (total chol), HDL cholesterol, non-HDL cholesterol, and triglyceride in female B6-Apoe ${ }^{-/-}$ $(n=8)$ and C3H-Apoe ${ }^{-/-}$mice $(n=8)$ fed a Western diet. Values are the mean \pm SE. ${ }^{*} p<0.05$.

HDL cholesterol levels and reduced HDL cholesterol levels (Fig. 2). C3H-Apoe ${ }^{-/-}$mice $(n=8)$ had significantly higher plasma levels of total $(902.7 \pm 59.2$ vs. $681.4 \pm 36.5$ $\mathrm{mg} / \mathrm{dL} ; p=0.0016)$, non-HDL (875.1 \pm 56.6 vs. $606.3 \pm$ $36.7 \mathrm{mg} / \mathrm{dL} ; p=0.002)$, HDL cholesterol ( $27.5 \pm 5.5$ vs. $12.1 \pm 0.6 \mathrm{mg} / \mathrm{dL} ; p=0.025)$, and triglycerides $(136.6 \pm$ 
Fig. 3. Common atherosclerosis developed in the carotid arteries without interruption of blood flow in $\mathrm{B} 6-\mathrm{Apoe}^{-/-}$and $\mathrm{C} 3 \mathrm{H}$ Apoe $^{-/-}$mice fed a Western diet for 12 weeks. a Gross appearance of atherosclerosis in the carotid arteries of a B6-Apoe ${ }^{-/-}$ mouse. Black arrows point toward an atherosclerotic plaque in the bifurcation (left) and branch (right). b, c Oil red O-stained sections of the left common carotid artery of a B6-Apoe - $^{-/}$and a C3H-Apoe ${ }^{-/-}$mouse. The B6-Apoe ${ }^{-/-}$mouse developed an advanced lesion containing fatty, fibrous, necrotic, and calcium components, while the C3H-Apoe ${ }^{-/-}$mouse had no lesion. d Morphometric measurement of atherosclerotic lesions in the left carotid artery of B6$\mathrm{Apoe}^{-/-}$and $\mathrm{C} 3 \mathrm{H}-\mathrm{Apoe}^{-/-}$mice. Results are the mean \pm SE of 14 female B6-Apoe ${ }^{-/-}$ and 8 female C3H-Apoe ${ }^{-/-}$mice.

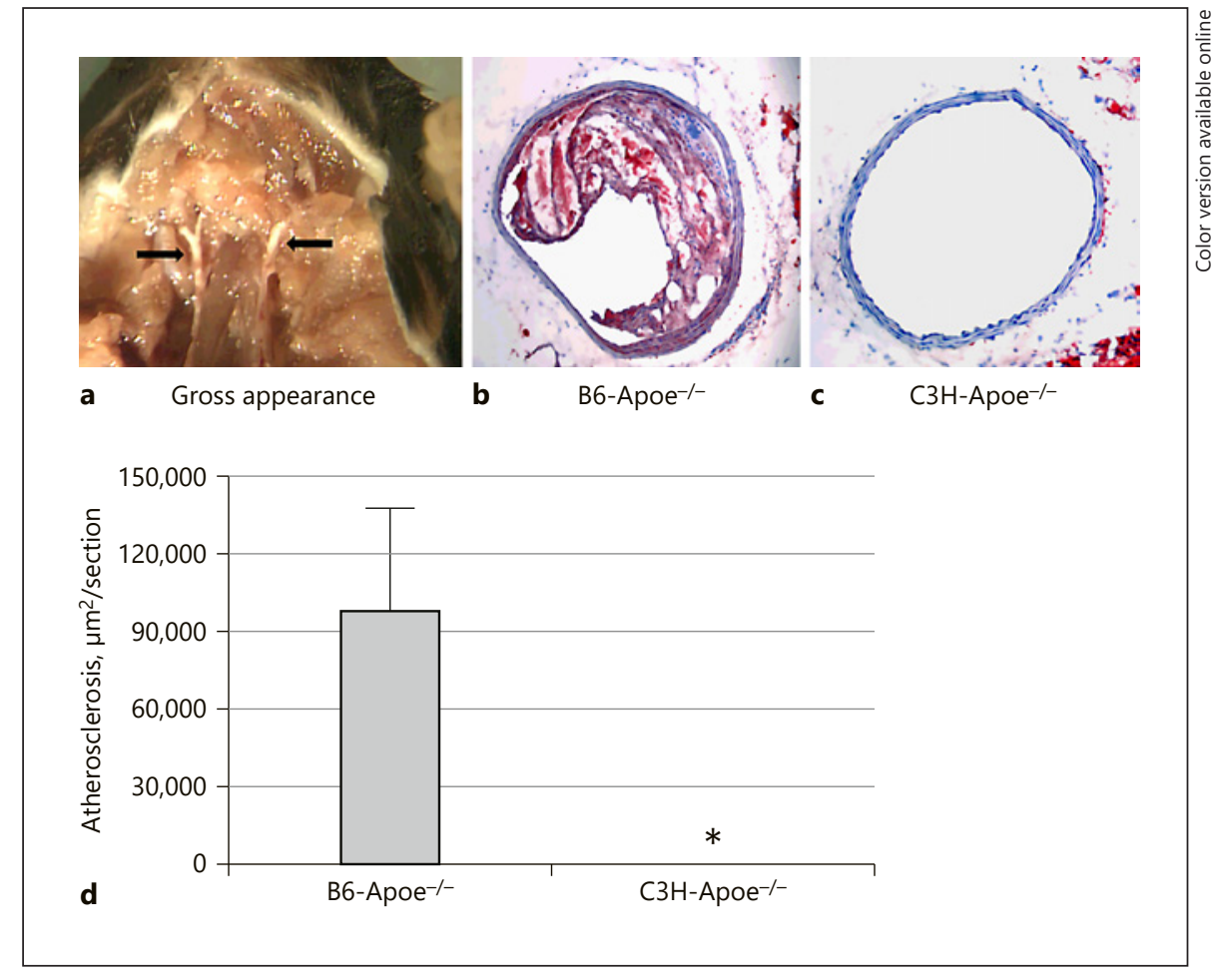

8.2 vs. $112.1 \pm 5.3 \mathrm{mg} / \mathrm{dL} ; p=0.028)$ than B6-Apoe ${ }^{-/-}$mice $(n=8)$.

\section{Atherosclerosis in the Carotid Artery without Interrupted Blood Flow}

Atherosclerotic lesions in the carotid arteries of B6Apoe $^{-/-}$and $\mathrm{C} 3 \mathrm{H}-\mathrm{Apoe}^{-/-}$mice were examined after being fed a Western diet for 12 weeks. Atherosclerosis around the bifurcation of the right and left common carotid arteries was grossly observable in B6-Apoe ${ }^{-/-}$mice (Fig. 3a). Atherosclerotic lesions in the left common carotid artery were measured on oil red $\mathrm{O}$ stained sections (Fig. 3b, c). B6-Apoe ${ }^{-/}$mice developed advanced atherosclerotic lesions containing lipid, fibrous component, calcification, and necrotic areas. The average lesion size of these mice was $98,019 \pm 10,594 \mu \mathrm{m}^{2} /$ section $(n=14)$. In striking contrast, $\mathrm{C} 3 \mathrm{H}-\mathrm{Apoe}^{-/-}$mice developed no lesion (Fig. 3d; $p=4.4 \mathrm{E}-7 ; n=8$ ).

\section{Lesion Formation in the Carotid Artery with Interrupted Blood Flow}

Morphometric measurements of the ligated left common carotid artery and the contralateral right common carotid artery were compared between B6-Apoe ${ }^{-/-}$and $\mathrm{C} 3 \mathrm{H}-\mathrm{Apoe}^{-/-}$mice at 1,2 , and 4 weeks after surgery. At all 3 time points examined, B6-Apoe ${ }^{-/-}$mice developed larger intimal lesions than $\mathrm{C} 3 \mathrm{H}-\mathrm{Apoe}^{-/-}$mice in the ligated artery (Fig. 4a). The difference between the two strains in lesion size at 4 weeks was highly significant ( $p=0.0017 ; n=5$ per strain). The medial area of the ligated artery in $\mathrm{B} 6-\mathrm{Apoe}^{-/-}$mice at this time point was also larger than that of $\mathrm{C} 3 \mathrm{H}-\mathrm{Apoe}^{-/-}$mice, although the difference did not reach statistical significance (Fig. $4 \mathrm{~b} ; p=$ 0.138). Compared to the contralateral control artery, the ligated artery showed a significant increase in medial area at 4 weeks after ligation in B6-Apoe ${ }^{-/-}$mice (Fig. $4 c ; p=$ 0.0245).

The areas encircled by the external or internal elastic lamina of the ligated artery were comparable between the two strains at 1 and 2 weeks of ligation (Fig. 4d, e). At 4 weeks, the areas were significantly larger in B6-Apoe ${ }^{-/-}$ mice than in $\mathrm{C} 3 \mathrm{H}-\mathrm{Apoe}^{-/-}$mice $(p=0.0036$ and 0.0045 , respectively), indicating that the ligated artery of B6Apoe $^{-/-}$mice underwent a positive remodeling.

There was no intimal lesion in the contralateral right carotid artery of both strains. The medial area of the artery was comparable between the two strains at all 3 time points examined (Fig. 4c).

Histological analysis showed that lesions occurred in ligated arteries of B6-Apoe ${ }^{-/-}$mice as early as 1 week after 
Intimal lesion
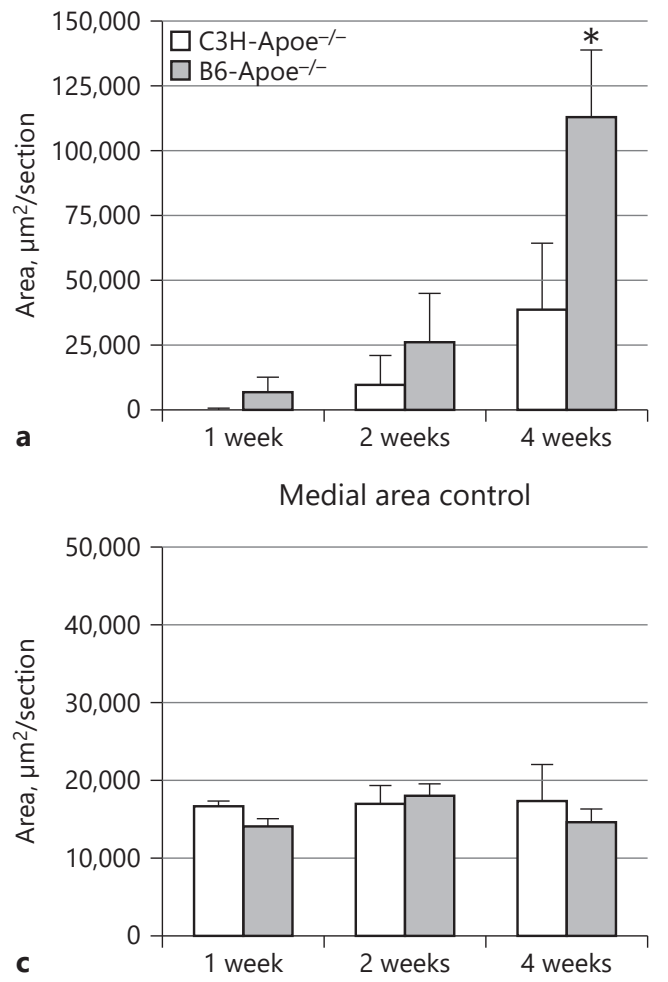

Area within internal elastic lamina

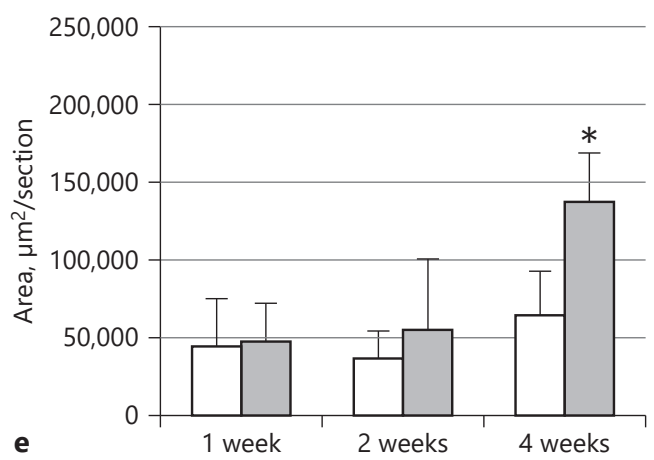

Medial area ligated

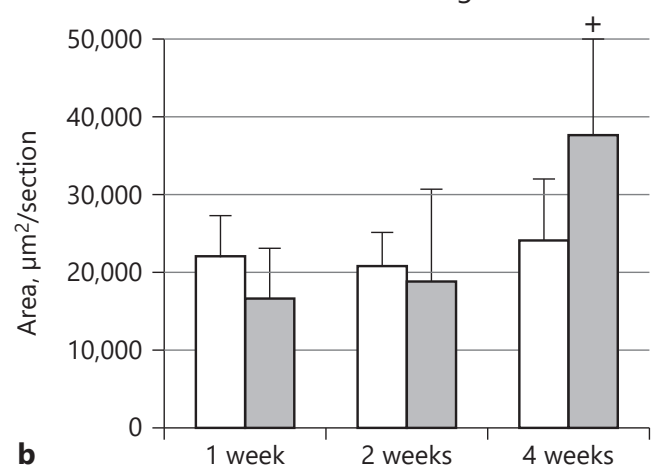

Area within external elastic lamina

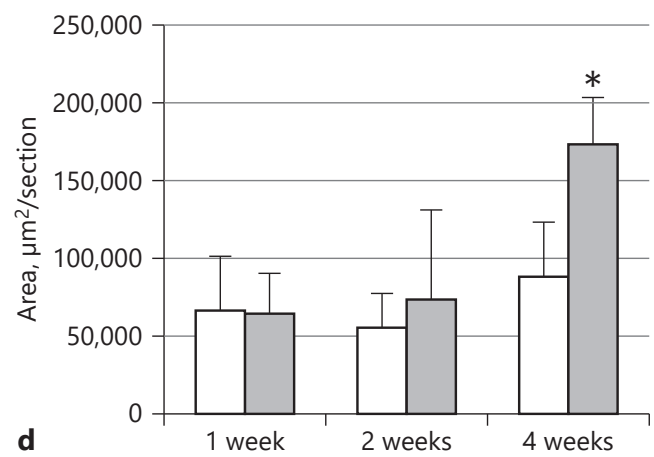

Fig. 4. Quantitative measurements of intimal (a) and medial areas (b) in the ligated left common carotid artery and medial areas in the contralateral right common carotid artery (c) of B6-Apoe ${ }^{-/-}$ and $\mathrm{C} 3 \mathrm{H}-\mathrm{Apoe}^{-/-}$mice fed a Western diet. Cross-sectional areas encircled by the external elastic lamina (d) and internal elastic lamina (e) in the ligated common artery were also measured. Measure- ments were made on the carotid arteries 1 ( 3 mice per strain), 2 (5 C3H-Apoe ${ }^{-/-}$and 4 B6-Apoe ${ }^{-/-}$mice), and 4 weeks (5 mice per strain) after ligation. Values are the mean \pm SE for each group. ${ }^{*} p<0.05$ versus $\mathrm{C} 3 \mathrm{H}-$ Apoe $^{-/-}$mice; ${ }^{+} p<0.05$ versus the contralateral common carotid artery. ligation, and after 2 weeks in C3H-Apoe ${ }^{-/-}$mice (Fig. 5). These lesions were small and consisted of 1 or 2 layers of cells overlaying the inner surface of the arteries. The lesions of B6-Apoe ${ }^{-/-}$mice looked foamy, while the lesions of $\mathrm{C} 3 \mathrm{H}-\mathrm{Apoe}^{-/-}$mice consisted of mononuclear cells adhering to the surface of the endothelial lining (Fig. 5a, e). With increasing duration, the lesions progressed to intermediate or fibrous lesions containing multiple layers of 


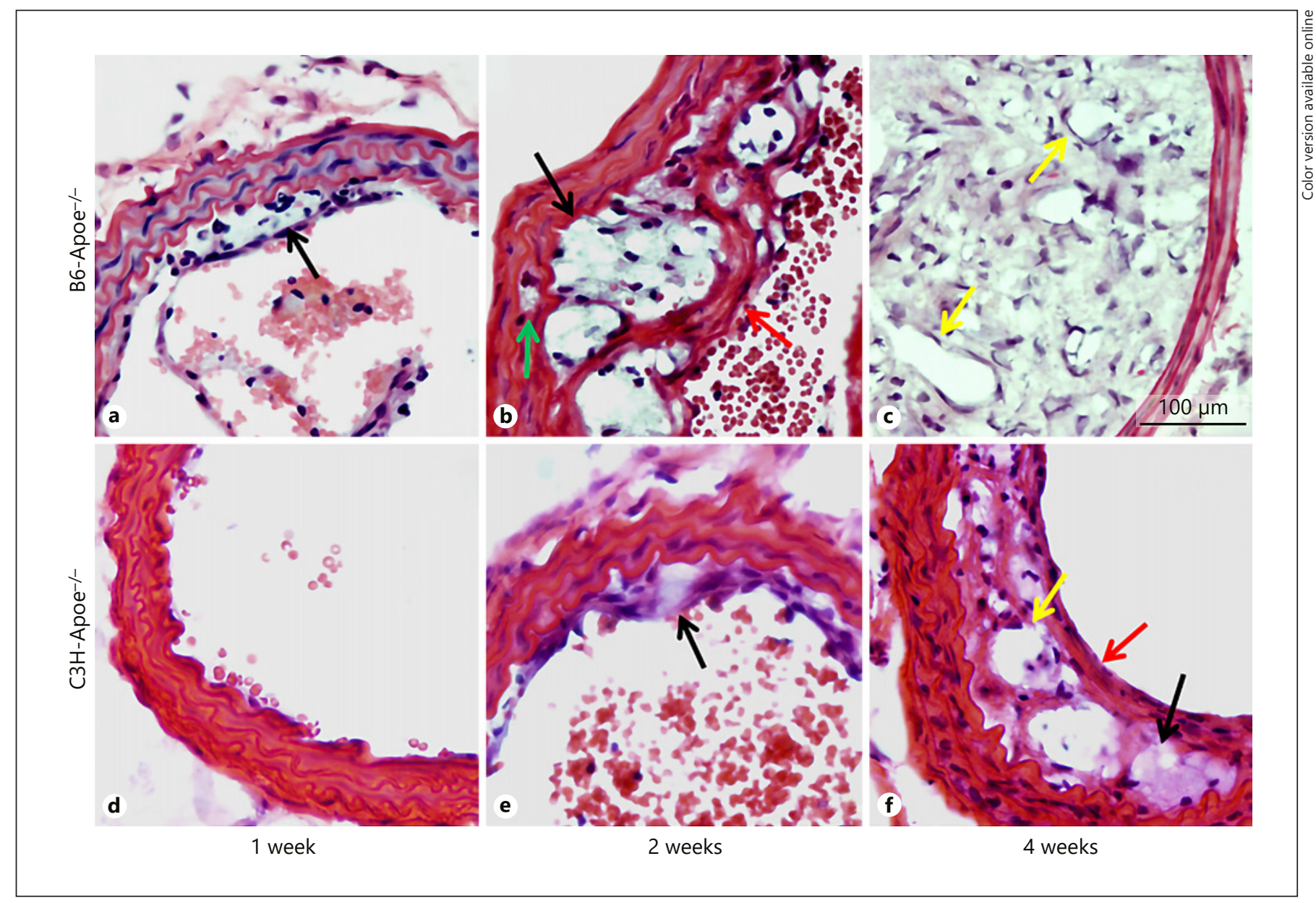

Fig. 5. Representative images of cross-sections of ligated common carotid arteries from B6-Apoe ${ }^{-/-}$and $\mathrm{C} 3 \mathrm{H}-\mathrm{Apoe}^{-/-}$mice 1, 2, and 4 weeks after ligation. The top row shows cross-sections of the vessels from B6-Apoe ${ }^{-/-}$mice (a-c), and the bottom row shows crosssections of $\mathrm{C} 3 \mathrm{H}-\mathrm{Apoe}^{-/-}$mice $(\mathbf{d}-\mathbf{f})$. Black arrows point toward foam cells, red arrows toward fibrous caps, and yellow arrows to neovessels. Foam cells can be observed in the medial area of the ligated vessel (b, green arrow). Sections were stained with the standard HE method. Original magnification $\times 40$. foam cells, smooth muscle cells, and fibrous elements. The fibrous lesions were observable at 2 weeks after ligation in

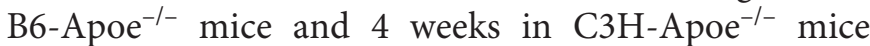
(Fig. 5b, f). By 4 weeks, the lesions of B6-Apoe ${ }^{-/-}$mice progressed to more advanced lesions, containing neo-vessels and substantially narrowing the vessel lumen (Fig. 5c).

The deposition of lipids in the arterial walls of the ligated carotid artery and the contralateral carotid artery was evaluated using oil red $\mathrm{O}$ stain. Lipid deposition was observed in the medial wall of the ligated arteries, starting on day 1 and increased over time in B6-Apoe ${ }^{-/-}$mice (Fig. 6). The contralateral artery also showed staining in the medial wall on day 3 and later time points after surgery, although less prominent compared to the ligated artery. Lipid deposition was also seen in the medial wall of the ligated artery at all time points tested and was increasingly prominent at later time points in $\mathrm{C} 3 \mathrm{H}-\mathrm{Apoe}^{-/-}$ mice. The contralateral carotid artery showed less staining in the medial wall with oil red $\mathrm{O}$.

\section{Cytological Differences between the Intimal Lesions of} B6-Apoe ${ }^{-/-}$Mice and C3H-Apoe ${ }^{-/-}$Mice

To evaluate possible mechanisms that may explain strain-dependent differences in lesion formation, we characterized major cellular components that potentially play roles in atherosclerosis. Specific cellular components were determined by immunohistochemical analyses. At the earlier time examined (day 1 through to 1 week), sporadic neutrophil adhesion to the endothelium was observed in both strains (Fig. 7a). At later time points, neu- 


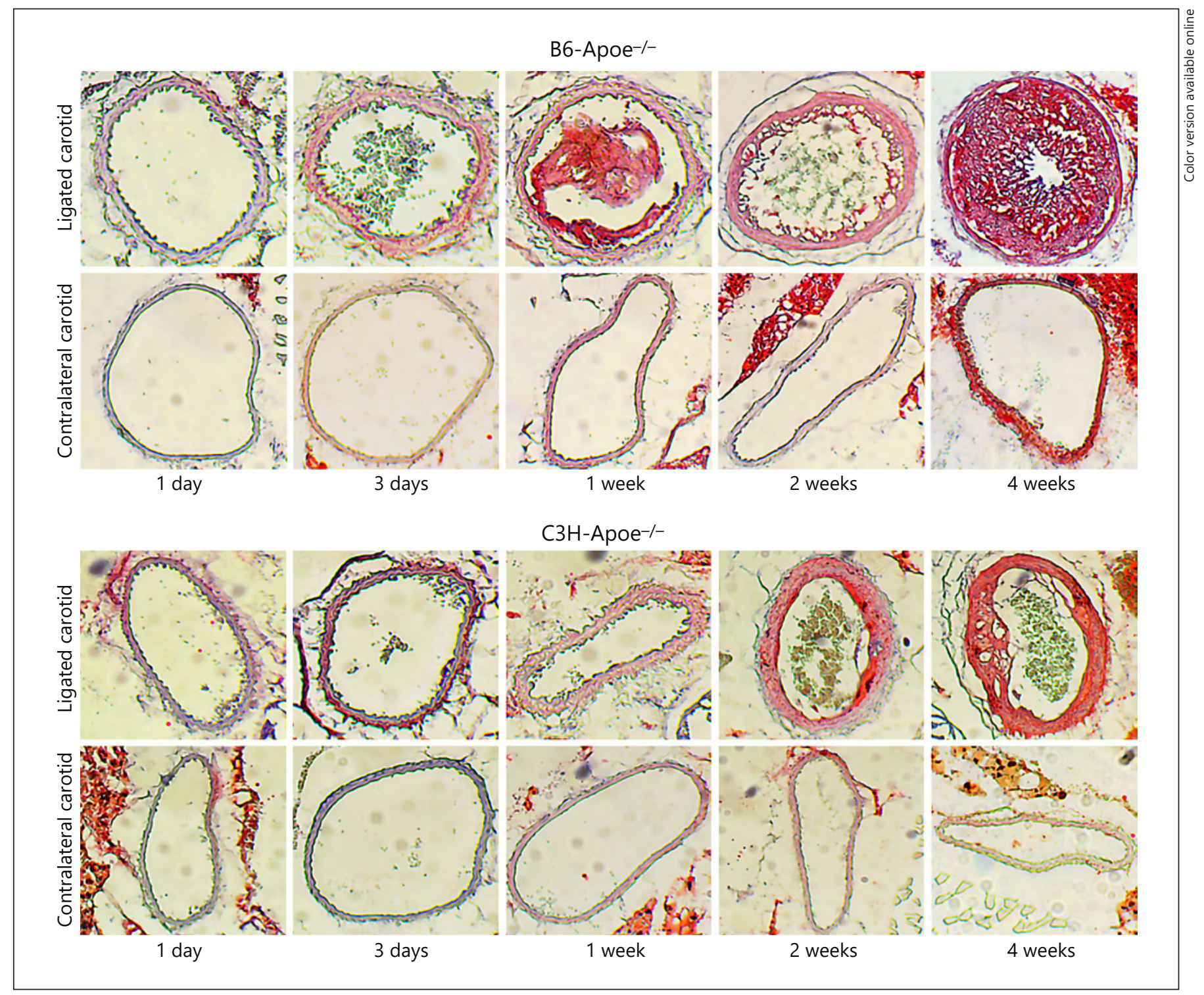

Fig. 6. Oil red O-stained sections of ligated common carotid arteries and contralateral right carotid arteries of B6- $\mathrm{Apoe}^{-/-}$and $\mathrm{C} 3 \mathrm{H}-$ $\mathrm{Apoe}^{-/-}$mice fed a Western diet. Intimal lesions are stained red. Note the time-dependent increase in red intensity for the medial

trophils were observed within the lesions of both strains, although $\mathrm{C} 3 \mathrm{H}-\mathrm{Apoe}^{-/-}$mice had many more.

Although foam cells were observed histologically as early as 1 week after ligation, immunostaining for macrophages with the MOMA-2 antibody were only apparent at 2 and 4 weeks after ligation when significant intimal lesions formed (Fig. 7b). Fluorescent-labeled antibodies targeting Mac3 and FPR1 antigens confirmed the presence of macrophages in ligated arterial walls of B6Apoe $^{-/-}$mice 1 week after ligation (Fig. 7c). layer of both ligated and control arteries of B6-Apoe ${ }^{-/-}$mice and the differences in red stain between the medial arterial wall of left and right carotid arteries of $\mathrm{C} 3 \mathrm{H}-\mathrm{Apoe}^{-/-}$mice over time. Original magnification $\times 10$.

T lymphocytes were detected with antibodies against CD4 and CD8 antigens. Immunoreactivity to the CD4 antigen was observed in the lesions of $\mathrm{C} 3 \mathrm{H}-\mathrm{Apoe}^{-/-}$mice but not B6-Apoe ${ }^{-/-}$mice (Fig. 7d). CD8+ T cells were not detectable in the lesions of either strain (Fig. 7e).

Immunostaining for smooth muscle was initially observed in the caps of the lesion at 2 weeks after ligation for B6-Apoe ${ }^{-/-}$mice (Fig. 7f). As lesions progressed, a sheet of disorganized smooth muscle was observed at the bottom of the lesion and more smooth muscle was seen in 


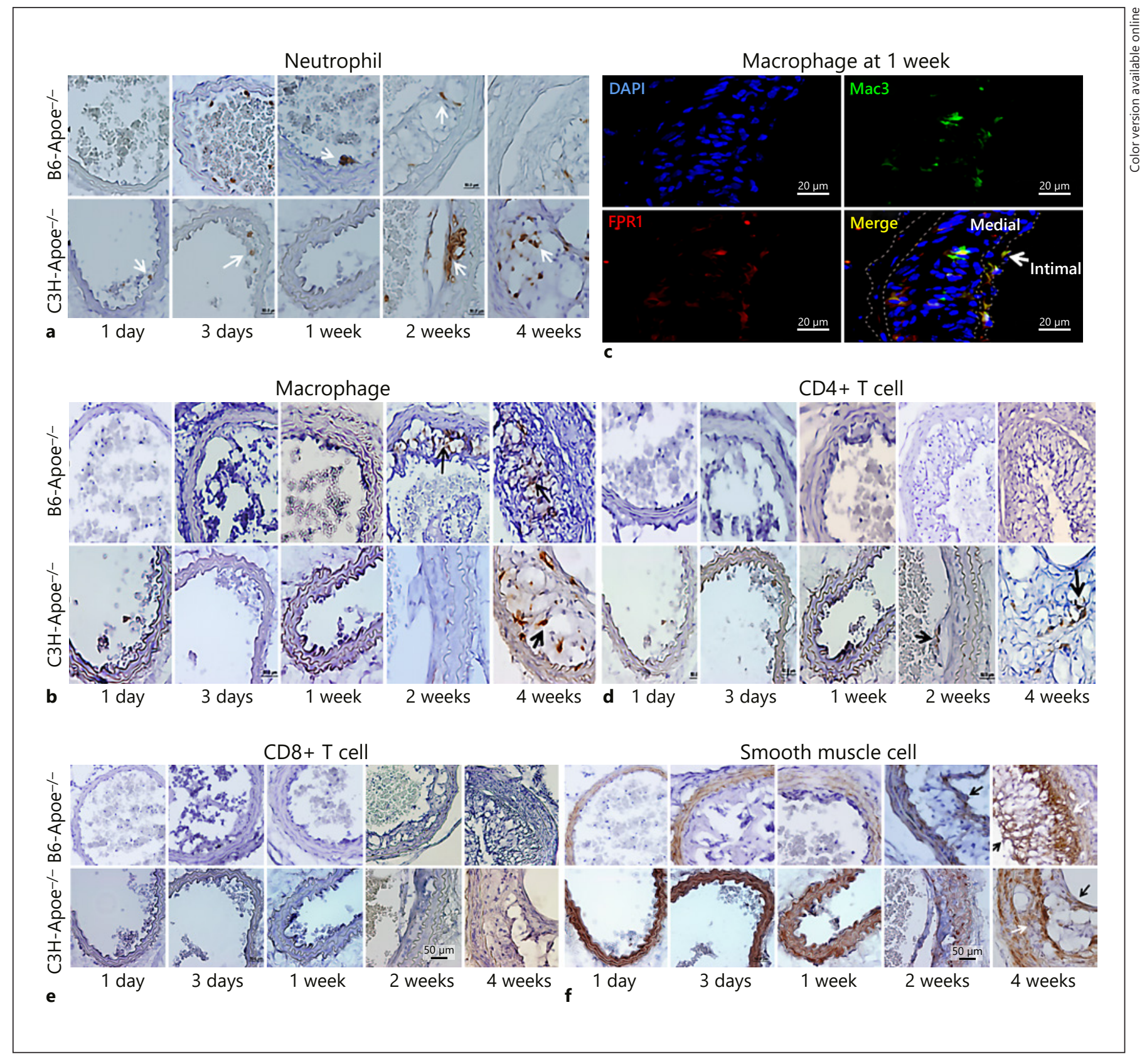

Fig. 7. Immunohistochemical detection of neutrophils (a), macrophages $(\mathbf{b}, \mathbf{c}), \mathrm{CD} 4+(\mathbf{d}), \mathrm{CD} 8+\mathrm{T}$ cells $(\mathbf{e})$, and smooth muscle cells (f) in ligated carotid arteries of $\mathrm{B} 6-\mathrm{Apoe}^{-/-}$and $\mathrm{C} 3 \mathrm{H}-\mathrm{Apoe}^{-/-}$mice fed a Western diet at different time points after ligation. a Section stained with the standard Avidin-Biotin complex method using an anti-Ly6G antibody. Arrows point to stained neutrophils. b Sections stained with rat monoclonal macrophage antibody MOMA2. Arrows point to stained macrophages. c Fluorescence double immunostaining showing the presence of macrophages in the ligated arterial wall of B6-Apoe ${ }^{-/-}$mice 1 week after ligation. Mac- rophages were stained with antibodies against Mac3 and FPR1 antigens. Nuclei were stained with DAPI. d Note the presence of $\mathrm{CD} 4+$ cells in intimal lesions of $\mathrm{C} 3 \mathrm{H}-\mathrm{Apoe}^{-/-}$mice but not B6Apoe $^{-/-}$mice. e Immunostaining for CD8+ T cells. No CD8+ cells were detectable in the lesions. $f$ Immunostaining for $a$-smooth muscle actin. Black arrows point to smooth muscle in the caps and white arrows point at disorganized smooth muscle at the bottom of the lesion. Note the low immunoreactivity to $\alpha$-smooth muscle actin of the medial arterial wall in B6-Apoe ${ }^{-/-}$mice 4 weeks after ligation. 

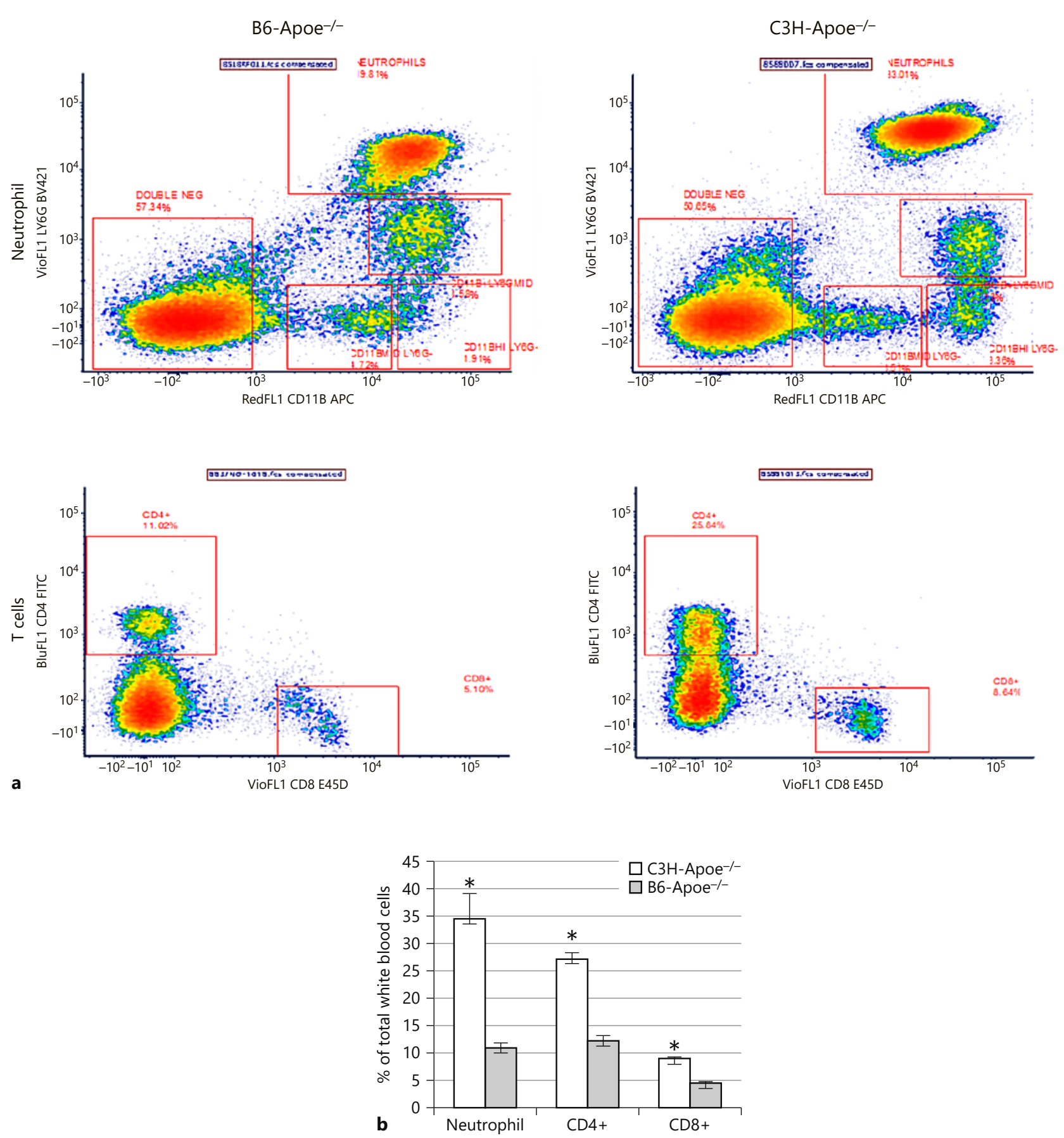

Fig. 8. Flow cytometric analysis of neutrophils, CD4+, and CD8+ $\mathrm{T}$ cells in the peripheral blood of male $\mathrm{B} 6-\mathrm{Apoe}^{-/-}$and $\mathrm{C} 3 \mathrm{H}-$ $\mathrm{Apoe}^{-/-}$mice fed a chow diet. a Representative results of flow cytometry analysis of neutrophils, CD4+, and CD8+ T cells on a CD45-positive gate. Neutrophils were gated for expression of both
CD11b and Ly6G antigens, T cells were gated for expression of CD4+ or CD8+ antigen. $\mathbf{b}$ Mean percentage of neutrophils, CD4+, and CD8+ cell populations as a percentage of CD45-positive leukocytes. Results are the mean \pm SE of 3 mice per strain. ${ }^{*} p<0.05$. 


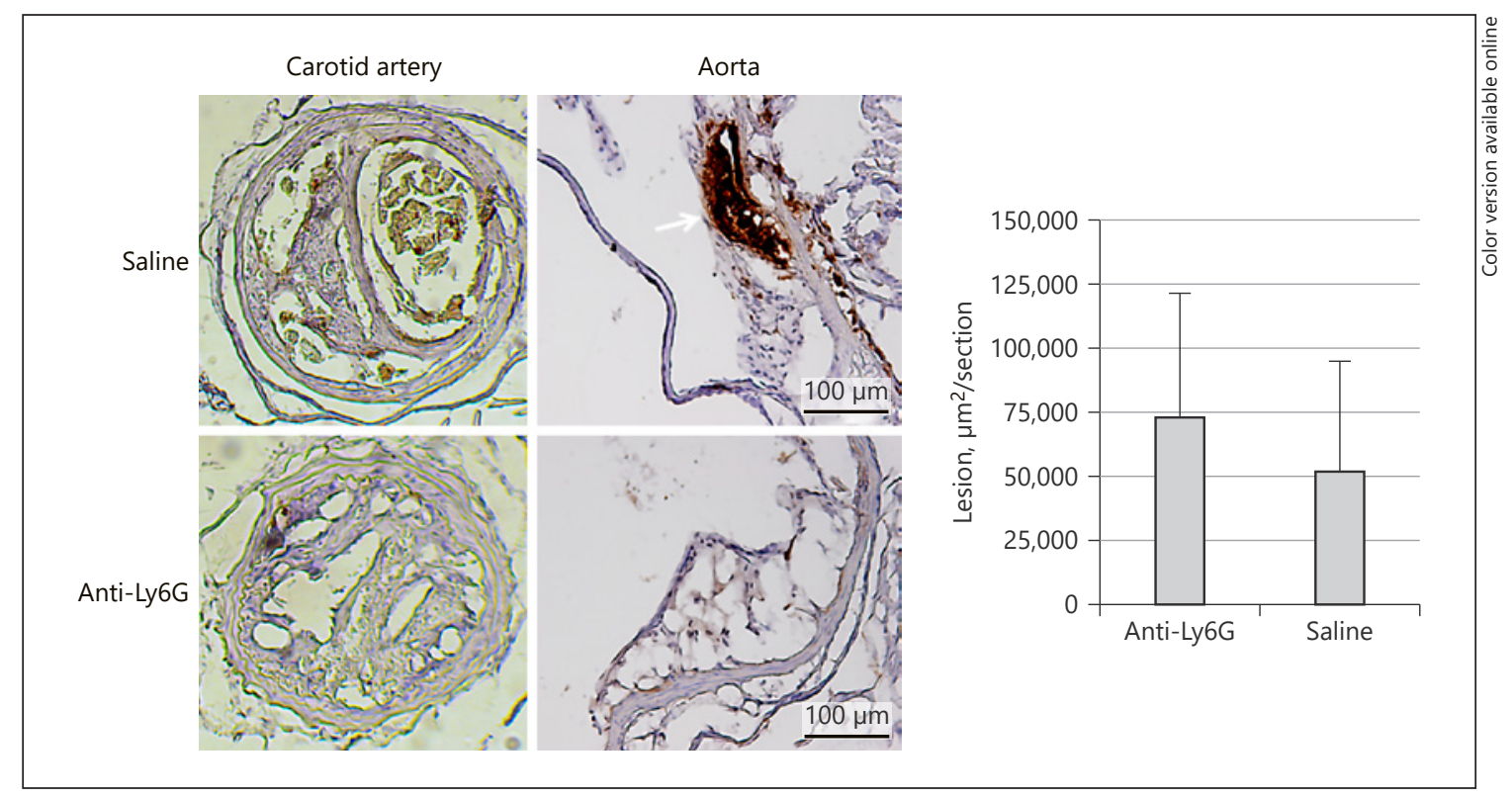

Fig. 9. Effect of anti-Ly6G antibody on lesion formation in the ligated carotid artery of B6-Apoe ${ }^{-/-}$mice. Mice were injected with $200 \mu \mathrm{g}$ of antibody every other day for 4 weeks. Immunostaining was performed to determine the presence of neutrophils in atherosclerotic lesions in the ligated carotid artery and aortic root. Arrows point to stained neutrophils. The bar graph shows the lesion size in the ligated artery of antibody-treated and control mice 4 weeks after ligation. Results are the means \pm SE of 4 mice (both sexes) per group.

the cap of the lesion. The two smooth muscle layers were separated by a layer of foam cells containing fewer smooth muscle cells. For C3H-Apoe ${ }^{-/-}$mice, smooth muscle cells were intermingled with foam cells or other components of the lesions in the ligated artery 4 weeks after ligation. A decline in the immunoreactivity to $\alpha$-smooth muscle actin was observed in the medial layer of ligated arteries for both strains (Fig. 7f). At 4 weeks, the medial layer underlying the lesions showed little staining although smooth muscle within the lesions showed strong staining in B6-Apoe ${ }^{-/-}$mice.

Flow Cytometric Analysis of Blood Neutrophils and T Lymphocytes

Peripheral blood neutrophils and T cells from 3 male B6-Apoe ${ }^{-/-}$and C3H-Apoe ${ }^{-/-}$mice were analyzed by flow cytometry. Neutrophils were identified as CD11b and Ly6 $\mathrm{G}$ double positive cells and T cells were identified as CD4+ or CD8+ cells following positive selection for the common leukocyte antigen CD45 (Fig. 8a). Neutrophils accounted for $34.4 \pm 0.8 \%$ of total leukocytes in $\mathrm{C} 3 \mathrm{H}$ Apoe $^{-/-}$mice, significantly higher than the $11.0 \pm 4.5 \%$ in B6-Apoe ${ }^{-/-}$mice ( $p=0.036$; Fig. 8b). C3H-Apoe ${ }^{-/-}$mice also had a higher percentage of CD $4+$ cells $(27.1 \pm 0.9$ vs. $12.1 \pm 1.0 ; p=0.0004)$ and CD $8+$ cells $(8.8 \pm 0.4$ vs. $4.5 \pm$
$0.4 ; p=0.0014)$ compared to B6-Apoe ${ }^{-/-}$mice. The number of leukocytes was counted after removal of red blood cells: $\mathrm{C} 3 \mathrm{H}-\mathrm{Apoe}^{-/-}$mice had significantly more leukocytes than B6-Apoe ${ }^{-/-}$mice $(5.27 \pm 0.59$ vs. $1.53 \pm 0.12 \times$ $10^{6} / \mathrm{mL} ; p=0.021$ ).

\section{Treatment with Antibody Targeting Neutrophils}

To evaluate the role of neutrophils in lesion formation, 4-week-old Mep1 $\alpha^{-/-}$Apoe $^{-/-}$mice with the B6 genetic background began receiving a 4-week treatment with the anti-Ly6 G antibody every other day. Antibody treatment led to the elimination of neutrophils in atherosclerotic lesions in the ligated carotid artery and aorta (Fig. 9). Mice treated with the antibody did not show a significant difference in lesion size from control mice $(72,714 \pm 24,265$ vs. $51,414 \pm 21,621 \mu^{2} /$ section; $p=0.537 ; n=4$ per group).

\section{Discussion}

To date, strain-dependent differences in atherosclerotic formation among mouse strains have primarily been observed from the aortic root or other parts of the aorta $[11,13-15,23]$. These differences have provided the bases 
of linkage mapping for finding genetic factors in atherogenesis [24-26]. Few studies have been performed to look at strain-dependent differences in atherosclerosis at sites beyond the aorta in mice [27]. One major reason for the rarity of studies is that mouse strains do not develop atherosclerosis at sites beyond the aorta unless they are genetically modified to become deficient in Apoe or Ldlr, or to overexpress Apoe 3 or Pcsk9. Our effort to find genetic factors in atherosclerosis has led us to the creation of multiple Apoe $^{-/-}$mouse strains [13]. Although a number of loci for carotid atherosclerosis have been mapped in intercrosses derived from the Apoe ${ }^{-/-}$mouse strains $[18,26$, 28 ], the characterization of carotid atherosclerosis with these strains has not been reported. In this study we used two different models to characterize atherosclerotic formation in the carotid artery of $\mathrm{B} 6-\mathrm{Apoe}^{-/-}$and $\mathrm{C} 3 \mathrm{H}-$ $\mathrm{Apoe}^{-/-}$mice, and demonstrated the dramatic effect of the genetic background and blood flow on atherogenesis in the vessel. The lesions formed in the carotid artery of B6Apoe $^{-/-}$mice with normal blood flow were similar to those in humans: they occurred at the bifurcation of the vessel, contained lipid, fibrous components, calcification and necrosis, and were dramatically affected by the genetic background (Fig. 3). The lesions developed in the ligated carotid artery were also similar to what are seen in humans, progressing from a fatty streak consisting of foam cells to fibrous lesion comprised of foam cells and fibrous element to advanced lesion containing neovessels.

An intriguing finding of this study is that $\mathrm{C} 3 \mathrm{H}-\mathrm{Apoe}^{-/-}$ mice were totally resistant to atherosclerosis, developing no atherosclerosis in the carotid artery even after being fed a Western diet for 12 weeks. In contrast, B6-Apoe ${ }^{-/}$ mice developed advanced atherosclerotic lesions in the vessel. On the Western diet, B6-Apoe ${ }^{-/-}$and C3H-Apoe ${ }^{-/-}$ mice developed severe hypercholesterolemia largely due to elevations in non-HDL cholesterol. As C3H-Apoe ${ }^{-/-}$ mice had higher non-HDL cholesterol and triglyceride levels and a comparable HDL cholesterol level relative to B6-Apoe ${ }^{-/-}$mice, their resistance to atherosclerosis should not be attributable to plasma lipids. In a recent study, we found that $\mathrm{C} 3 \mathrm{H}-\mathrm{Apoe}^{-/-}$mice fed a Western diet for 12 weeks developed considerable atherosclerotic lesions in the aortic root [13]. Local factors, particularly hemodynamic forces [29], are probably responsible for the difference between the two sites in plaque formation. Indeed, blood flow in the aortic sinus is highly unsteady and turbulent [30] compared to the flow in the carotid bifurcation.

This study shows that $\mathrm{C} 3 \mathrm{H}-\mathrm{Apoe}^{-/-}$mice developed both early and intermediate atherosclerotic lesions in the carotid artery once blood flow was interrupted. Foam cells, the hallmark of early atherosclerosis, were observed histologically on HE sections. Immunocytochemical analysis demonstrates the presence of lipid-laden macrophages in the lesions. In mice, foam cells are primarily macrophage derived and only a tiny fraction of them is derived from smooth muscle cells [31]. Smooth muscle cells are slow in outgrowth [32], and these cells were only observed in thelesions 2 weeks after ligation. The MOMA2 antibody is effective in detecting monocytes and macrophages in various mouse tissues, but it is less sensitive in detecting marginal zone macrophages. As FPR1 and Mac3 are also specifically expressed by macrophages [20, 33], we used these antigens to demonstrate the infiltration of macrophages in arterial walls at the early stage of plaque formation. As the lesions progressed, smooth muscle cells appeared and made up the fibrous caps of the plaques. Though rare, neovessels and necrotic areas were also observed in the lesions.

Compared to B6-Apoe ${ }^{-/-}$mice, $\mathrm{C} 3 \mathrm{H}-\mathrm{Apoe}^{-/-}$mice developed smaller lesions in the ligated artery at the time points examined and showed delays in plaque initiation and progression. Foam cells were observed as early as 1 week after ligation in B6-Apoe ${ }^{-/-}$mice but 2 weeks in $\mathrm{C} 3 \mathrm{H}-$ Apoe $^{-/-}$mice. Fibrous caps formed 2 weeks after ligation in $\mathrm{B} 6-\mathrm{Apoe}^{-/-}$but 4 weeks in $\mathrm{C} 3 \mathrm{H}-\mathrm{Apoe}^{-/-}$mice. By 4 weeks, the last time point of observation, B6-Apoe ${ }^{-/}$ mice developed advanced lesions containing numerous neovessels and occluding the lumen of the affected vessel.

A previous study has shown that intimal growth in the ligated carotid artery is minimal in wild-type $\mathrm{B} 6$ and $\mathrm{C} 3 \mathrm{H}$ mice 4 weeks after ligation [34]. In contrast, $\mathrm{C} 3 \mathrm{H}-\mathrm{Apoe}^{-/-}$ and B6-Apoe ${ }^{-/-}$mice developed medium and large sized intimal lesions in the ligated artery, respectively. The absence of Apoe and the resultant hyperlipidemia should be responsible for increased lesion formation in the $\mathrm{Apoe}^{-/-}$ strains. Indeed, Apoe inhibits and hyperlipidemia promotes smooth muscle cell proliferation and vascular remodeling [12, 17, 35].

Lipid retention in the medial wall of the ligated artery showed a progressive increase in both $\mathrm{Apoe}^{-{ }^{--}}$strains as denoted on oil red $\mathrm{O}$ staining. The contralateral control artery also showed mild staining in B6-Apoe ${ }^{-/-}$mice but the staining was less obvious in $\mathrm{C} 3 \mathrm{H}-\mathrm{Apoe}^{-/-}$mice. This finding is consistent with our previous observation that

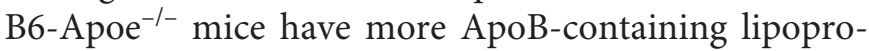
teins in the aortic wall than $\mathrm{C} 3 \mathrm{H}-\mathrm{Apoe}^{-/-}$mice [36]. Deposition of lipoproteins, specifically low-density lipoprotein (LDL), in the arterial walls is the initial event in the development of atherosclerosis. The deposited LDL un- 
dergoes oxidative modification by vascular cells to become oxidized LDL, which stimulates vascular wall cells to express proinflammatory molecules and promotes foam cell formation.

Ligation in the distal end near the bifurcation causes blood flow cessation in the common carotid artery, although the vessel may still experience arterial blood pressure and pulsation. This would increase the interactions between white blood cells and the endothelium in the ligated artery. Neutrophils were observed to adhere to the lining endothelium and to be present in the lesions. Activated neutrophils release superoxide and proinflammatory molecules at the sites of adhesion that promote the recruitment of monocytes and alter endothelial cell properties [37]. The role of neutrophils in lesion formation was determined through depleting mice of the cells with anti-Ly6G antibody. The effectiveness of neutrophil depletion with specific anti-Ly6G antibody in mice has been confirmed in multiple studies [38-40]. In this study we confirmed the elimination of neutrophils in atherosclerotic lesions of antibody-treated mice. The present finding that mice treated with the anti-Ly6G antibody showed a little increase in plaque size suggests that neutrophils play a minor protective role in atherosclerosis. The finding that $\mathrm{C} 3 \mathrm{H}-\mathrm{Apoe}^{-/-}$mice had more neutrophils in the lesions supports this speculation. We previously observed that $\mathrm{F} 1$ mice reconstituted with bone marrow from $\mathrm{C} 3 \mathrm{H}$ Apoe $^{-/-}$mice developed a carotid lesion comparable to those reconstituted with B6-Apoe ${ }^{-/-}$bone marrow following endothelium denudation injury [41], suggesting that bone marrow-derived cells contribute little to the difference between the two strains in carotid atherosclerosis. Previous studies also reported the presence of neutrophils in atherosclerotic lesions of Apoe ${ }^{-/-}$mice $[42,43]$, while depletion of neutrophils with Ly6G antibody only reduced early but had no effect on advanced aortic lesions in Apoe $^{-/-}$mice [43].

T helper (CD4) cells can promote or protect against atherosclerosis depending on the experimental models used and the stage of plaque formation [44]. We observed the presence of $\mathrm{CD} 4$ cells in intimal lesions of $\mathrm{C} 3 \mathrm{H}$ Apoe $^{-/-}$but not B6-Apoe ${ }^{-/-}$mice, although their significance to the difference between the two strains in lesion formation remains to be defined. The current cytometric analysis of peripheral blood leukocytes showed that $\mathrm{C} 3 \mathrm{H}$ Apoe $^{-/-}$mice have more neutrophils and CD4+ T cells than B6-Apoe ${ }^{-/-}$mice, which is in agreement with the results observed by Petkova et al. [45] in wild-type B6 and $\mathrm{C} 3 \mathrm{H}$ mice. The higher percentage of neutrophils and $\mathrm{CD} 4+\mathrm{T}$ cells in peripheral blood could be partially re- sponsible for the enhanced infiltration of CD4+ T cells and neutrophils in the intimal lesions of $\mathrm{C} 3 \mathrm{H}-\mathrm{Apoe}^{-/-}$ mice. The absence of CD8+ T cells in atherosclerotic lesions precludes their substantial role in plaque formation.

The unresponsiveness of arterial wall cells to oxidized $\mathrm{LDL}$ may be responsible for the resistance of $\mathrm{C} 3 \mathrm{H}-\mathrm{Apoe}^{-/-}$ mice to lesion formation in the ligated artery. We previously observed that endothelial cells and vascular smooth muscle cells of $\mathrm{B} 6$ mice exhibit a dramatic induction of MCP-1, CSF-1, VCAM-1, and heme oxygenase-1 in response to oxidized $\mathrm{LDL}$, while cells from $\mathrm{C} 3 \mathrm{H}$ mice showed little induction [11, 32, 46]. MCP-1, CSF-1, and VCAM-1 are primarily associated with the recruitment and differentiation of monocytes. Thus, if arterial wall cells of $\mathrm{C} 3 \mathrm{H}$ mice were unable to recruit monocytes to the artery wall and promote their differentiation into macrophages, it might be expected that these mice would develop less atherosclerosis. Through aorta and bone marrow transplantations, we demonstrated that the arterial wall is a major source of variation in the atherosclerosis susceptibility of the two strains [11,47].

Wild-type mouse strains, including $\mathrm{B} 6$ and $\mathrm{C} 3 \mathrm{H}$, show significant negative remodeling or shrinkage of the ligated carotid artery [34]. In contrast, this phenomenon was not found in the two Apoe ${ }^{-/-}$strains; rather, the ligated artery of B6-Apoe ${ }^{-/-}$mice showed an increase in the areas encircled by the internal or external elastic lamina 4 weeks after ligation. This finding is consistent with compensatory enlargement of atherosclerotic coronary arteries observed in humans [48]. Smooth muscle cells are the main cellular component of intimal lesions in ligated carotid arteries of wild-type mice [49], while the intimal lesions contain macrophages and other inflammatory cells in Apoe $^{-/-}$mice. Smooth muscle cells and the extracellular matrix produced by the cells restrict vessel distension [50], while macrophages produce MMP-9, MMP-12, and other enzymes that degrade the extracellular matrix [51]. The degradation of the extracellular matrix underlying atherosclerotic plaques is expected to weaken the vessel wall and enhance blood pressure-induced outward remodeling of vessels $[51,52]$. Indeed, a higher macrophage count and lipid content is significantly associated with positive remodeling in human coronary arteries with plaques [53, 54].

In this study, the mice that received the left common carotid artery ligation developed no symptoms of stroke. This finding is consistent with the observation Kumar and Lindner [49] made in wild-type mice. The brain receives blood from two sets of arteries: the vertebral arteries, which arise from the subclavian arteries, and the in- 
ternal carotid arteries, which arise from the common carotid arteries. The right and left vertebral arteries merge on the front surface of the brainstem at the midline to form the basilar artery, which joins the blood supply from the internal carotid arteries through the circle of Willis. The conjoining of the two major sources of cerebral blood supply via the circle of Willis improves the chances of any region of the brain to continue receiving blood when one of the major arteries becomes occluded. In mice, both the left and right common carotid arteries have to be occluded to induce stroke and brain damage [55].

In conclusion, the present study has demonstrated the significance of the genetic background, blood flow, and inflammation in the development of atherosclerosis in the carotid artery of hyperlipidemic mouse strains. Despite severe hyperlipidemia developed on the Western diet, $\mathrm{C} 3 \mathrm{H}-\mathrm{Apoe}^{-/-}$mice formed no atherosclerosis in the carotid artery with normal blood flow. Once the blood flow was interrupted, $\mathrm{C} 3 \mathrm{H}-\mathrm{Apoe}^{-/-}$mice developed moderate atherosclerotic lesions in the ligated artery, although they were smaller than in B6-Apoe ${ }^{-/}$mice. Thus, blood flow is a major force that determines atherosclerosis susceptibility in the carotid arteries. Interruption of blood flow increases the chances of attachment and recruitment of white blood cells to the arterial wall in which lipoproteins accumulate and are subsequently oxidized. Oxidized lipids induce atherosclerosis by promoting inflam- mation and foam cell formation. The ligation model relates to clinical situations of obstructive arterial disease and restenosis in humans. It is useful for unraveling the cellular and molecular processes of atherosclerosis, a complex human disease.

\section{Acknowledgments}

The authors acknowledge receipt of the following financial support for the research, authorship, and/or publication of this article: the work was supported by National Institutes of Health grants DK116768 and Commonwealth Health Research Board (CHRB) Award. Andrew Grainger is a recipient of the Robert R. Wagner Fellowship from the University of Virginia School of Medicine.

\section{Statement of Ethics}

All animal-related procedures were performed in compliance with the NIH guide for the care and use of laboratory animals and approved by the University of Virginia Institutional Animal Care and Use Committee (animal protocol No. 3109).

\section{Disclosure Statement}

The authors have no conflicts of interest to declare.

\section{References}

1 Benjamin EJ, Virani SS, Callaway CW, Chamberlain AM, Chang AR, Cheng S, et al.; American Heart Association Council on Epidemiology and Prevention Statistics Committee and Stroke Statistics Subcommittee. Heart disease and stroke statistics - 2018 update: a report from the American Heart Association. Circulation. 2018 Mar;137(12):e67-492.

2 Paraskevas KI, Mikhailidis DP, Liapis CD. Internal carotid artery occlusion: association with atherosclerotic disease in other arterial beds and vascular risk factors. Angiology. 2007;58(3):329-35

3 Paciaroni M, Caso V, Venti M, Milia P, Kappelle LJ, Silvestrelli G, et al. Outcome in patients with stroke associated with internal carotid artery occlusion. Cerebrovasc Dis. 2005; 20(2):108-13.

4 Rothwell PM, Warlow CP. Low risk of ischemic stroke in patients with reduced internal carotid artery lumen diameter distal to severe symptomatic carotid stenosis: cerebral protection due to low poststenotic flow? On behalf of the European Carotid Surgery Trialists' Collaborative Group. Stroke. 2000 Mar;31(3): $622-30$.
5 Manzano JJ, De Silva DA, Pascual JL, Chang $\mathrm{HM}$, Wong MC, Chen CP. Associations of ankle-brachial index (ABI) with cerebral arterial disease and vascular events following ischemic stroke. Atherosclerosis. 2012 Jul;223(1):21922.

6 Razzouk L, Rockman CB, Patel MR, Guo Y, Adelman MA, Riles TS, et al. Co-existence of vascular disease in different arterial beds: peripheral artery disease and carotid artery stenosis-Data from Life Line Screening $\left({ }^{\circledR}\right)$. Atherosclerosis. 2015 Aug;241(2): 687-91.

7 Chang Z, Huangfu C, Grainger AT, Zhang J, Guo Q, Shi W. Accelerated atherogenesis in completely ligated common carotid artery of apolipoprotein E-deficient mice. Oncotarget. 2017 Nov;8(66):110289-99.

8 Eschert H, Sindermann JR, Scheld HH, Breithardt G, Weissen-Plenz G. Vascular remodeling in ApoE-deficient mice: diet dependent modulation after carotid ligation. Atherosclerosis. 2009 May;204(1):96-104.

9 Nam D, Ni CW, Rezvan A, Suo J, Budzyn K, Llanos A, et al. Partial carotid ligation is a model of acutely induced disturbed flow, leading to rapid endothelial dysfunction and atherosclerosis. Am J Physiol Heart Circ Physiol. 2009 Oct;297(4):H1535-43.

10 Shin IJ, Shon SM, Schellingerhout D, Park JY, Kim JY, Lee SK, et al. Characterization of partial ligation-induced carotid atherosclerosis model using dual-modality molecular imaging in ApoE knock-out mice. PLoS One. 2013 Sep; 8(9):e73451.

11 Shi W, Wang NJ, Shih DM, Sun VZ, Wang X, Lusis AJ. Determinants of atherosclerosis susceptibility in the $\mathrm{C} 3 \mathrm{H}$ and $\mathrm{C} 57 \mathrm{BL} / 6$ mouse model: evidence for involvement of endothelial cells but not blood cells or cholesterol metabolism. Circ Res. 2000 May;86(10):107884.

12 Tian J, Pei H, James JC, Li Y, Matsumoto AH, Helm GA, et al. Circulating adhesion molecules in apoE-deficient mouse strains with different atherosclerosis susceptibility. Biochem Biophys Res Commun. 2005 Apr;329(3):11027.

13 Liu S, Li J, Chen MH, Liu Z, Shi W. Variation in Type 2 Diabetes-Related Phenotypes among Apolipoprotein E-Deficient Mouse Strains. PLoS One. 2015 May; 10(5):e0120935. 
14 Paigen B, Morrow A, Brandon C, Mitchell D, Holmes P. Variation in susceptibility to atherosclerosis among inbred strains of mice. Atherosclerosis. 1985 Oct;57(1):65-73.

15 Bennett BJ, Davis RC, Civelek M, Orozco L, Wu J, Qi H, et al. Genetic architecture of atherosclerosis in mice: a systems genetics analysis of common inbred strains. PLoS Genet. 2015 Dec;11(12):e1005711.

16 Nigro P, Abe J, Berk BC. Flow shear stress and atherosclerosis: a matter of site specificity. Antioxid Redox Signal. 2011 Sep;15(5):1405-14.

17 Tian J, Pei H, Sanders JM, Angle JF, Sarembock IJ, Matsumoto AH, et al. Hyperlipidemia is a major determinant of neointimal formation in LDL receptor-deficient mice. Biochem Biophys Res Commun. 2006 Jul;345(3):1004-9.

18 Li Q, Li Y, Zhang Z, Gilbert TR, Matsumoto $\mathrm{AH}$, Dobrin SE, et al. Quantitative trait locus analysis of carotid atherosclerosis in an intercross between $\mathrm{C} 57 \mathrm{BL} / 6$ and $\mathrm{C} 3 \mathrm{H}$ apolipoprotein E-deficient mice. Stroke. 2008 Jan;39(1): 166-73.

19 Yuan Z, Pei H, Roberts DJ, Zhang Z, Rowlan JS, Matsumoto AH, et al. Quantitative trait locus analysis of neointimal formation in an intercross between C57BL/6 and $\mathrm{C} 3 \mathrm{H} / \mathrm{HeJ}$ apolipoprotein E-deficient mice. Circ Cardiovasc Genet. 2009 Jun;2(3):220-8.

20 Zhang Y, Kundu B, Zhong M, Huang T, Li J, Chordia MD, et al. PET imaging detection of macrophages with a formyl peptide receptor antagonist. Nucl Med Biol. 2015 Apr;42(4): 381-6.

21 Li J, Wang Q, Chai W, Chen MH, Liu Z, Shi W. Hyperglycemia in apolipoprotein E-deficient mouse strains with different atherosclerosis susceptibility. Cardiovasc Diabetol. 2011 Dec; 10(1):117.

22 Bruhn KW, Dekitani K, Nielsen TB, Pantapalangkoor P, Spellberg B. Ly6G-mediated depletion of neutrophils is dependent on macrophages. Results Immunol. 2015 Dec;6:5-7.

23 Tomita H, Zhilicheva S, Kim S, Maeda N. Aortic arch curvature and atherosclerosis have overlapping quantitative trait loci in a cross between 129S6/SvEvTac and C57BL/6J apolipoprotein E-null mice. Circ Res. 2010 Apr;106(6): 1052-60.

24 Su Z, Li Y, James JC, McDuffie M, Matsumoto $\mathrm{AH}$, Helm GA, et al. Quantitative trait locus analysis of atherosclerosis in an intercross between $\mathrm{C} 57 \mathrm{BL} / 6$ and $\mathrm{C} 3 \mathrm{H}$ mice carrying the mutant apolipoprotein E gene. Genetics. 2006 Mar;172(3):1799-807.

25 Zhang Z, Rowlan JS, Wang Q, Shi W. Genetic analysis of atherosclerosis and glucose homeostasis in an intercross between C57BL/6 and $\mathrm{BALB} / \mathrm{cJ}$ apolipoprotein E-deficient mice. Circ Cardiovasc Genet. 2012 Apr;5(2):190-201.

26 Rowlan JS, Zhang Z, Wang Q, Fang Y, Shi W. New quantitative trait loci for carotid atherosclerosis identified in an intercross derived from apolipoprotein E-deficient mouse strains. Physiol Genomics. 2013 Apr;45(8):332-42.

27 Shim J, Handberg A, Ostergren C, Falk E, Bentzon JF. Genetic susceptibility of the arte- rial wall is an important determinant of atherosclerosis in $\mathrm{C} 57 \mathrm{BL} / 6$ and $\mathrm{FVB} / \mathrm{N}$ mouse strains. Arterioscler Thromb Vasc Biol. 2011 Aug;31(8):1814-20.

28 Grainger AT, Jones MB, Chen MH, Shi W. Polygenic Control of Carotid Atherosclerosis in a BALB/cJ $\times \mathrm{SM} / J$ Intercross and a Combined Cross Involving Multiple Mouse Strains. G3 (Bethesda). 2017 Feb;7(2):731-9.

29 VanderLaan PA, Reardon CA, Getz GS. Site specificity of atherosclerosis: site-selective responses to atherosclerotic modulators. Arterioscler Thromb Vasc Biol. 2004 Jan;24(1):1222.

30 Bäck M, Gasser TC, Michel JB, Caligiuri G. Biomechanical factors in the biology of aortic wall and aortic valve diseases. Cardiovasc Res. 2013 Jul;99(2):232-41.

31 Allahverdian S, Pannu PS, Francis GA. Contribution of monocyte-derived macrophages and smooth muscle cells to arterial foam cell formation. Cardiovasc Res. 2012 Jul;95(2):16572.

32 Shi W, Haberland ME, Jien ML, Shih DM, Lusis AJ. Endothelial responses to oxidized lipoproteins determine genetic susceptibility to atherosclerosis in mice. Circulation. $2000 \mathrm{Jul}$; 102(1):75-81.

33 Khazen W, M'bika JP, Tomkiewicz C, Benelli C, Chany C, Achour A, et al. Expression of macrophage-selective markers in human and rodent adipocytes. FEBS Lett. 2005 Oct; 579(25):5631-4.

34 Harmon KJ, Couper LL, Lindner V. Strain-dependent vascular remodeling phenotypes in inbred mice. Am J Pathol. 2000 May;156(5): 1741-8.

35 Zhu B, Kuhel DG, Witte DP, Hui DY. Apolipoprotein $\mathrm{E}$ inhibits neointimal hyperplasia after arterial injury in mice. Am J Pathol. 2000 Dec;157(6):1839-48

36 Brown MD, Jin L, Jien ML, Matsumoto AH, Helm GA, Lusis AJ, et al. Lipid retention in the arterial wall of two mouse strains with different atherosclerosis susceptibility. J Lipid Res. 2004 Jun;45(6):1155-61.

37 Soehnlein O, Weber C, Lindbom L. Neutrophil granule proteins tune monocytic cell function. Trends Immunol. 2009 Nov;30(11):538-46.

38 Abbitt KB, Cotter MJ, Ridger VC, Crossman DC, Hellewell PG, Norman KE. Antibody ligation of murine Ly-6G induces neutropenia, blood flow cessation, and death via complement-dependent and independent mechanisms. J Leukoc Biol. 2009 Jan;85(1):55-63.

39 Tate MD, Ioannidis LJ, Croker B, Brown LE, Brooks AG, Reading PC. The role of neutrophils during mild and severe influenza virus infections of mice. PLoS One. 2011 Mar; 6(3):e17618

40 Daley JM, Thomay AA, Connolly MD, Reichner JS, Albina JE. Use of Ly6G-specific monoclonal antibody to deplete neutrophils in mice. J Leukoc Biol. 2008 Jan;83(1):64-70.

41 Shi W, Pei H, Fischer JJ, James JC, Angle JF, Matsumoto AH, et al. Neointimal formation in two apolipoprotein E-deficient mouse strains with different atherosclerosis susceptibility. J Lipid Res. 2004 Nov;45(11):2008-14.

42 Rotzius P, Thams S, Soehnlein O, Kenne E, Tseng CN, Björkström NK, et al. Distinct infiltration of neutrophils in lesion shoulders in ApoE-/- mice. Am J Pathol. 2010 Jul;177(1): 493-500.

43 Drechsler M, Megens RT, van Zandvoort M, Weber C, Soehnlein O. Hyperlipidemia-triggered neutrophilia promotes early atherosclerosis. Circulation. 2010 Nov;122(18):1837-45.

44 Grönberg C, Nilsson J, Wigren M. Recent advances on CD4+ T cells in atherosclerosis and its implications for therapy. Eur J Pharmacol. 2017 Dec;816:58-66.

45 Petkova SB, Yuan R, Tsaih SW, Schott W, Roopenian DC, Paigen B. Genetic influence on immune phenotype revealed strain-specific variations in peripheral blood lineages. Physiol Genomics. 2008 Aug;34(3):304-14.

46 Miyoshi T, Tian J, Matsumoto AH, Shi W. Differential response of vascular smooth muscle cells to oxidized LDL in mouse strains with different atherosclerosis susceptibility. Atherosclerosis. 2006 Nov; 189(1):99-105.

47 Pei H, Wang Y, Miyoshi T, Zhang Z, Matsumoto AH, Helm GA, et al. Direct evidence for a crucial role of the arterial wall in control of atherosclerosis susceptibility. Circulation. 2006 Nov; 114(22):2382-9.

48 Glagov S, Weisenberg E, Zarins CK, Stankunavicius R, Kolettis GJ. Compensatory enlargement of human atherosclerotic coronary arteries. N Engl J Med. 1987 May;316(22): 1371-5.

49 Kumar A, Lindner V. Remodeling with neointima formation in the mouse carotid artery after cessation of blood flow. Arterioscler Thromb Vasc Biol. 1997 Oct;17(10):2238-44.

50 Wagenseil JE, Mecham RP. Vascular extracellular matrix and arterial mechanics. Physiol Rev. 2009 Jul;89(3):957-89.

51 Shi W, Brown MD, Wang X, Wong J, Kallmes $\mathrm{DF}$, Matsumoto $\mathrm{AH}$, et al. Genetic backgrounds but not sizes of atherosclerotic lesions determine medial destruction in the aortic root of apolipoprotein E-deficient mice. Arterioscler Thromb Vasc Biol. 2003 Oct;23(10): 1901-6.

52 Hayashi K, Makino A, Kakoi D. Remodeling of arterial wall: response to changes in both blood flow and blood pressure. J Mech Behav Biomed Mater. 2018 Jan;77:475-84.

53 Ota H, Magalhaes MA, Torguson R, Negi S, Kollmer MR, Spad MA, et al. The influence of lipid-containing plaque composition assessed by near-infrared spectroscopy on coronary lesion remodelling. Eur Heart J Cardiovasc Imaging. 2016 Jul;17(7):821-31.

54 Varnava AM, Mills PG, Davies MJ. Relationship between coronary artery remodeling and plaque vulnerability. Circulation. $2002 \mathrm{Feb}$; 105(8):939-43

55 Shibata M, Ohtani R, Ihara M, Tomimoto H. White matter lesions and glial activation in a novel mouse model of chronic cerebral hypoperfusion. Stroke. 2004 Nov;35(11):2598-603. 